\title{
Schopenhauer como educador: o esboço de misantropia filosófica de Nietzsche
}

\author{
Schopenhauer as educator: the sketch of Nietzsche's philosophical misanthropy
}

\author{
Jarlee Salviano \\ Doutor em Filosofia pela USP, \\ Professor Adjunto da Universidade Federal da Bahia (UFBA), \\ Coordenador do GT Schopenhauer da ANPOF. \\ E-mail: jarlee.salviano@ufba.br
}

\begin{abstract}
Resumo: Em 1874 Nietzsche publicou sua terceira Consideração Extemporânea - Schopenhauer como educador. Trata-se de mais um importante episódio desta complicada relação entre os dois filósofos. A filosofia schopenhaueriana, pela sua extemporaneidade, sua crítica severa e solitária à cultura da época e à filosofia universitária, serve ao jovem Nietzsche na construção do modelo ideal da nova cultura dos homens superiores, no seio da qual seria possível o engendramento do autêntico filósofo e do gênio na arte. Trata-se então de verificar os detalhes desta luta que o autor das Extemporâneas trava consigo mesmo nesta tentativa de conciliar sua veneração por Schopenhauer e sua negação de princípios metafísicos da tradição, na qual será incluída posteriormente a filosofia de Schopenhauer.
\end{abstract}

Palavras-chave: Schopenhauer; Nietzsche; terceira Consideração Extemporânea.

\begin{abstract}
In 1874 Nietzsche published his third Untimely Meditation - Schopenhauer as Educator. This is another important episode of this complicated relationship between the two philosophers. Schopenhauer's philosophy, because his untimely character, his severe and solitary critical to the culture of his time, and to the university philosophy, serves to the young Nietzsche to the build of the ideal model of the new culture of superior human, within which could be the engendering of the authentic philosopher and genius in the art. It is then to verify the details of this struggle that the author of Untimely Meditations hangs himself in trying to reconcile his veneration for Schopenhauer and his denial of metaphysical principles of tradition, which will be included later the philosophy of Schopenhauer.
\end{abstract}

Keywords: Schopenhauer; Nietzsche; third Unfashionable Observation.

Em 1873 Nietzsche publica seu segundo livro, o ensaio Consideração Extemporânea - David Strauss, o devoto e o escritor. Outras extemporâneas foram projetadas; a seguinte se chamaria $A$ doença histórica e as posteriores teriam como títulos: O Estado; A cidade; A crise social; A cultura guerreira; A religião. No entanto, a segunda Extemporânea, vinda a público no início de 1874, ganhou o título menos polêmico de Da utilidade e desvantagem da história para a vida. No final do mesmo ano surgiu a terceira, Schopenhauer como Educador e em 1876 a quarta e última: Richard Wagner em Bayreuth.

Em sua autobiografia composta em 1888, Nietzsche confessa que as Extemporâneas falavam apenas dele mesmo, principalmente as duas últimas: "Schopenhauer e Wagner", sentencia ele em Ecce 
Homo, "ou em uma palavra, Nietzsche"; e conclui: "não é Schopenhauer como educador, porém seu oposto, Nietzsche como educador que toma a palavra"².

Resta então a questão: se é Nietzsche quem fala através de Schopenhauer na terceira Extemporânea, de que Nietzsche se trata então naquele escrito? A pergunta ganha um sentido inquietante se tivermos em vista a discrepância entre as posturas de Nietzsche em suas obras publicadas na juventude e os póstumos da mesma época.

Dois escritos de Schopenhauer servem de pano de fundo para a composição da Extemporânea que traz seu nome. Em primeiro lugar, o ensaio Sobre a filosofia universitária, que compõe o primeiro volume dos Parerga e Paralipomena, que é analisado por Nietzsche no último capítulo da Extemporânea; e também a Parábola dos porcos-espinhos, também presente nos Parerga, no capítulo 31 do segundo volume, que tem como título Alegorias, Parábolas e Fábulas. Esta parábola, na qual Schopenhauer compara a sociedade a uma família de porcos-espinhos no inverno, fora citada por Nietzsche em sua primeira publicação $O$ nascimento da tragédia. Ei-la:

\begin{abstract}
Um grupo de porcos-espinhos num frio dia de inverno se aglomerou para, através do aquecimento recíproco, não morrer de frio. Contudo, logo começam a sentir os espinhos uns dos outros, o que os leva então a se afastarem novamente. Quando a necessidade de aquecimento os aproxima mais uma vez, repete-se aquele segundo infortúnio. Neste vai-e-vem em meio aos dois sofrimentos, seguem até encontrarem uma distância segura entre eles, na qual podem melhor suportá-los. Do mesmo modo os homens são impelidos uns aos outros pelas necessidades da sociedade, de cujo seio surgem o vazio e a monotonia. Entretanto, suas particularidades assaz desagradáveis e defeitos insuportáveis os afastam mais uma vez. A distância mediana ao fim encontrada, na qual podem se reunir, são a polidez e os bons costumes (...) Quem no entanto tem muito de seu calor interno prefere ficar longe da sociedade, para não ser incomodado e não causar incômodo ${ }^{3}$. [grifo nosso]
\end{abstract}

A Extemporânea Schopenhauer como educador, de certo modo, procura dar continuidade a este esboço de misantropia schopenhaueriano.

Nietzsche inicia seu ensaio reclamando que por preguiça ou temor povos se escondem atrás dos costumes e opiniões, agem como animal de rebanho. Mas cada homem é único (unicum) e a educação deve, portanto, ajudar o indivíduo no encontro consigo mesmo: "Sê tu mesmo! Tu não és isto que agora fazes, pensas e desejas"4 (a prescrição pindárica que forma o subtítulo de sua autobiografia já se apresenta aqui). O melhor meio para isto é, diz Nietzsche, "lembrar de nossos mestres e educadores. É por isso que vou lembrar hoje o nome do único professor, o único mestre de quem eu posso me orgulhar, Arthur Schopenhauer" 5

\footnotetext{
${ }^{1}$ NIETZSCHE, Friedrich. Ecce Homo, p. 67.

${ }^{2}$ Idem, Ibidem, p. 71.

${ }^{3}$ Arthur Schopenhauer, Sämtliche Werke, V, Parerga und Paralipomena II, p. 765.

${ }^{4}$ NIETZSCHE, Friedrich. Consideração Extemporânea III, p. 162.

${ }^{5}$ Idem, Ibidem, p. 166.
} 
Tendo isto em vista, deve-se afirmar, antes de mais nada, que os educadores são verdadeiramente nossos libertadores.

Como deve ser realizada então, pergunta o jovem Nietzsche, esta educação através dos mestres? Deve visar o ponto forte, a virtude preponderante de cada indivíduo, ou a relação harmoniosa dos dons? Resposta: deve-se encontrar a força central e impedir que destrua as outras. Nietzsche tem em mente, na composição da terceira Extemporânea, a educação clássica, grega e romana. O principal alvo de sua crítica são os eruditos (Gelehrten), ou filisteus da cultura (Bildungsfilister), estes "dialéticos desenfreados" mergulhados numa "escolástica conceitual", que colocam a ciência acima da humanidade, nas mãos dos quais a educação tem como guia uma abstração inumana.

Nietzsche acompanha aqui a luta schopenhaueriana contra o abstracionismo hegeliano e a imagem do professor de filosofia representado nas figuras de Kant e Hegel. Curiosamente, tendo em vista o forte teor antiplatônico de escritos anteriores, como o ensaio Sobre verdade e mentira no sentido extramoral, a crítica nietzschiana desta Extemporânea se faz ouvir num tom inconfundivelmente platônico, no que diz respeito à defesa de uma cultura aristocrática e à crítica ao poder estatal vigente, em oposição ao pensamento democrático sofista.

Uma das causas deste distanciamento da virtude clássica da modernidade, segundo o filósofo, é a influência do cristianismo, a propagação da moral cristã.

O contato com Schopenhauer, em 1865, teria dado a Nietzsche o modelo deste verdadeiro educador que, devido à sua intempestividade, seria incompreendido pela atualidade, e que ensinaria a simplicidade, a honestidade, a serenidade e a constância, no pensamento e na vida. "Compreendo-o", diz o autor da Extemporânea, "como se ele tivesse escrito para mim"”. E isto porque, afirma Nietzsche, Schopenhauer foi um autor que escrevia para si mesmo; e não para os outros (o Estado e a religião vigente), ou em nome de um salário e uma posição social. Em última instância, escrevia como um pai que escreve para seu filho. Como artista, o mais poderoso exemplo deste educador seria Richard Wagner (os dois, juntamente com Beethoven e Goethe, representariam as naturezas de ferro que poderiam mudar a cultura alemã).

Com os escritos de Schopenhauer, "experimentamos então o mesmo sentimento de quando penetramos no bosque, respiramos profundamente e de repente nos sentimos bem de novo. Sentimos isso, há aí um ar sempre igual e fortificante" ${ }^{8}$ - que se compare esta passagem com a sentença de Nietzsche no Ecce Homo, que afirma estar sua primeira publicação, $O$ nascimento da tragédia, impregnada com o cadavérico aroma de Schopenhauer! $!^{9} 62$.

\footnotetext{
${ }^{6}$ Idem, Ibidem, p. 183.

${ }^{7}$ Idem, Ibidem, p. 171.

${ }^{8}$ Idem, Ibidem, p. 172.

${ }^{9}$ Idem, Ecce Homo, p. 62. 
Nietzsche lamenta, ainda, o fato de seu encontro com Schopenhauer ter sido meramente através dos livros:

[...] havia nisto uma grande deficiência. Eu me esforçava cada vez mais para ver através do livro e para representar o homem vivo, de quem eu tinha lido o grande testamento e que prometia não escolher para seus herdeiros senão aqueles que quisessem e pudessem ser mais do que simples leitores: quer dizer, seus filhos e seus discípulos ${ }^{10}$.

Schopenhauer, por sua vez, tivera a felicidade de estar em contato diretamente com a genialidade de Goethe, observa Nietzsche. Diferentemente de Schopenhauer, Kant "permaneceu atrelado à Universidade, se submeteu aos governantes, salvou as aparências de uma fé religiosa, suportou viver entre colegas e estudantes: é portanto natural que seu exemplo tenha produzido sobretudo professores de filosofia e uma filosofia de professores"11. Esta cultura filosófica da ciência pura, não pretende criar aborrecimentos aos poderes estabelecidos. Ligado a isto está, no campo da educação, a valorização crescente do ensino técnico.

Em contrapartida, Schopenhauer, o mais solitário e sofredor dos filósofos alemães, vivendo perigosamente em sua crítica ao Estado e à filosofia hegeliana predominante, não obtendo o reconhecimento tão buscado de sua obra, obteve como único consolo a companhia de Atma, seu fiel cão. Em todos os tempos, os filósofos solitários foram execrados, "pois a filosofia oferece ao homem um asilo onde nenhum tirano pode penetrar, a caverna da interioridade, o labirinto do coração: e isto deixa enfurecido os tiranos"12.

As palavras e atos destes homens excepcionais são explosões, erupção vulcânica, e trazem o risco da autodestruição. Têm eles a carência de companheiros: a falta de amor pode levá-los ao dilaceramento. No entanto, diz Nietzsche, "sempre há um semideus que suporta viver em condições tão terríveis, e viver vitoriosamente; e se por acaso quiserem ouvir os seus cantos solitários, ouçam a música de Beethoven""13.

Além do isolamento, Nietzsche aponta o outro perigo que acompanhou Schopenhauer por toda a vida: o desespero da verdade (Verzweiflung der Wahrheit). E isto devido à influência do racionalismo de Kant, tendo em vista ser Schopenhauer "um homem robusto e completo no sofrimento e desejo, e não

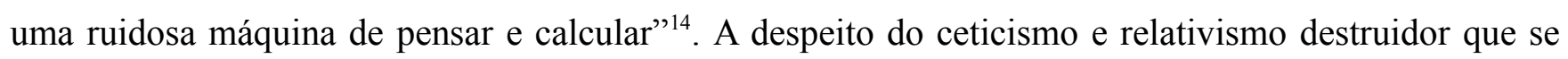
alastrou com a Crítica kantiana, na visão de Nietzsche, Schopenhauer seria "o guia que conduz das cavernas da melancolia cética ou da renúncia crítica para as alturas da contemplação trágica, com o céu

\footnotetext{
${ }^{10}$ Idem, Consideração Extemporânea III, p. 175.

${ }^{11}$ Idem, Ibidem, p. 176.

${ }^{12}$ Idem, Ibidem, p. 180.

${ }^{13}$ Idem, Ibidem, p. 181.

${ }^{14}$ Idem, Ibidem.
} 
noturno e suas estrelas no infinito acima de nós"15 - pode-se perceber claramente o quanto Nietzsche está aqui distante de sua crítica violenta posterior à moral da compaixão de Schopenhauer e seu niilismo passivo; e quão destoante está todo o elogio da verdade contido nesta Extemporânea, diante de escritos anteriores como o ensaio Sobre verdade e mentira e seus Cursos de retórica ministrados em Basel.

O terceiro e mais profundo perigo que ameaçou Schopenhauer foi a aspiração profunda pela genialidade e pela santidade: "aí reside a raiz de toda verdadeira cultura, e se entendo por esta palavra a nostalgia do homem que quer renascer como santo e como gênio, sei que não há necessidade de ser budista para compreender este mito"16. Ora, sabemos que o elogio schopenhaueriano do santo assenta-se na ideia da compaixão como fundamentação de toda moralidade, o que será duramente criticado nas outras fases do pensamento de Nietzsche. Vejamos mais adiante como isto se resolve no interior da terceira Extemporânea.

O combate de Schopenhauer contra a sua época era o combate contra tudo o que obstava a grandeza de espírito, pois ele não era filho de seu tempo, era um bastardo:

\begin{abstract}
Schopenhauer se levantou contra esta falsa mãe, vaidosa e indigna, a sua época, e expulsando-a, por assim dizer, de si, ele purificou e curou seu ser e se reencontrou na saúde e na pureza que lhe pertenciam. Eis porque é preciso se servir dos escritos de Schopenhauer como de um espelho da época, e não é evidentemente um defeito do espelho se tudo o que é atual só apareça nele como uma doença que desfigura, sob a forma de magreza e de palidez, os olhos vazios e as faces deprimidas, os sofrimentos reconhecíveis desta infância bastarda ${ }^{17}$.
\end{abstract}

Uma passagem da terceira Extemporânea não passa despercebida ao leitor de Schopenhauer: trata-se da identificação, no terceiro capítulo, da vida com a Vontade de viver (Wille zum Leben), tal como prescrevia Schopenhauer. Com isto se nota com clareza a distância deste Nietzsche da juventude daquele de Assim falou Zaratustra, em que, no capítulo Do superar a si mesmo, num diálogo entre a vida e Zaratustra, é decretada a sentença: “onde há vida também há vontade: mas não vontade de vida (Wille zum Leben), senão - é o que te ensino - vontade de poder (Wille zur Macht)"18. Este capítulo de Assim falou Zaratustra inicia-se com um conceito que foi central da terceira Extemporânea: a Vontade de verdade (Wille zur Wahrheit), que aparece lá como desespero da verdade, impulso à verdade (Trieb zur Wahrheit) ou amor à verdade (Liebe zur Wahrheit). Ali servia para caracterizar esta aspecto do erudito que ameaçava Schopenhauer, o qual não teria sucumbido a tal perigo, e por causa disto se tornara “o educador” para Nietzsche. Não é esta, certamente, a opinião de Zaratustra: tendo em vista que, ao que tudo indica, o capítulo Do superar a si mesmo é claramente direcionado a Schopenhauer,

\footnotetext{
${ }^{15}$ Idem, Ibidem, p. 182.

${ }^{16}$ Idem, Ibidem, p. 184.

${ }^{17}$ Idem, Ibidem, p. 190.

${ }^{18}$ Idem, Assim falou Zaratustra, p. 146.
} 
deveria então o autor de $O$ mundo como vontade e representação ser incluído entre "os mais sábios dos sábios (Weisesten)", impulsionados pela "vontade de que todo o existente possa ser pensado" ${ }^{19}$. No entanto, que não nos deixemos enganar, em Schopenhauer, o que ele chamou de sujeito puro do conhecimento é o antípoda do homem da ciência pura, o erudito da terceira Extemporânea: ele é a representação do gênio na arte ou do santo, e é descrito com as mesmas palavras que definirão, por exemplo, a individualidade dionisíaca de $O$ nascimento da tragédia, cuja "'eudade' [Ichheit] não é a mesma que a do homem empírico-real, desperto, mas sim a única 'eudade' verdadeiramente existente [seiende] e eterna, em repouso no fundo das coisas, mediante cujas imagens refletidas o gênio lírico penetra como o olhar até o cerne do ser"'20.

Schopenhauer serve também a Nietzsche para criticar a superficialidade da cultura jornalística da época, o endeusamento do Estado, visto como o fim supremo da humanidade pelos hegelianos - a hegeleria (Hegelei) -, e estabelecer a diferença entre o filósofo e os professores de filosofia, satisfeitos e submissos ao poder econômico do Estado em que vivem. Nietzsche, que, assim como Schopenhauer, tentou em vão seguir a carreira universitária como professor de filosofia, afirma que o Estado

obriga aqueles que escolhe a permanecer num lugar determinado, entre homens determinados, a aí exercerem uma atividade determinada; eles têm de instruir, todos os dias, em horários fixos, todos os jovens acadêmicos que manifestem desejo de instrução. Uma questão: poderia propriamente um filósofo, conscientemente, comprometer-se em ter todos os dias algo para ensinar? E ensinar isto a qualquer um que queira ouvi-lo? Não deve ele dar uma aparência de saber mais do que sabe? Não deve ele falar, diante de um auditório desconhecido, sobre coisas das quais somente poderia falar sem risco diante dos seus amigos mais próximos? E, em geral, não se despojaria ele da sua mais magnífica liberdade, aquela de seguir seu gênio, quando este o chama e para onde o chama - por estar comprometido a pensar publicamente, em horas determinadas, em coisas já fixadas previamente? E isto diante de jovens! Um tal pensamento não está, de antemão, como que emasculado? E se por acaso, num belo dia, ele tivesse a seguinte percepção: hoje, não posso pensar nada, nada de inteligente me vem ao espírito - e apesar disso, tivesse de ocupar seu posto e parecer pensar!??

Quando critica o erudito como aquele que transforma filosofia em história da filosofia, Nietzsche sentencia, com severidade:

E afinal de contas, o que importa a nossos jovens a história da filosofia? Devem eles ser desencorajados a ter opiniões, diante do montão confuso de todas as que existem? Devem eles também ser ensinados a entoar cantos jubilosos pelo muito que já tão magnificamente construímos? Devem eles porventura aprender a odiar e desprezar a filosofia? (...) E agora, que se imagine uma mente juvenil, sem muita experiência de vida em que são encerrados confusamente cinqüenta sistemas reduzidos a fórmulas e

\footnotetext{
${ }^{19}$ Idem, Ibidem, p. 143.

${ }^{20}$ Idem, O nascimento da tragédia, p. 44.

${ }^{21}$ Idem, Consideração Extemporânea III, p. 246-247. 
cinqüenta críticas destes sistemas - que desordem, que barbárie, que escárnio quando se trata da educação para a filosofia! $!^{22}$

Há, segundo Nietzsche, três imagens de homem em sua época: o homem da natureza de Rousseau; o homem contemplativo, espectador de grande estilo, representado pelo pensamento de Goethe; e o homem de Schopenhauer, "o tipo humano que domina em Schopenhauer ou em torno dele, como sua ideia platônica, por assim dizer" ${ }^{23}$ : mais ativo, que assume para si o sofrimento voluntário da veracidade $^{24}$. Pode-se concluir, assim, que "aquele que quer viver segundo Schopenhauer, este se parecerá sem dúvida mais com um Mefistófeles do que com um Fausto"25. De fato, o espírito negador de Schopenhauer certamente aparece, à época, ligado a todo tipo de malignidade:

Mas há uma maneira de negar e destruir que é precisamente um extravasamento desta poderosa aspiração à santificação e à salvação, da qual Schopenhauer foi para nós, homens profanos, homens seculares no sentido próprio do termo, o primeiro mestre filosófico. Toda existência que pode ser negada merece também ser negada; e ser verídico significa crer numa existência que não poderia absolutamente ser negada, crer numa existência que é ela própria verdadeira e sem mentira [grifo nosso]. É por isso que o homem verídico sente que sua atividade tem um sentido metafísico ${ }^{26}$.

Que estas palavras representam o pensamento de Schopenhauer, não há dúvida, mas até que ponto falam de Nietzsche, como é afirmado em Ecce Homo, é algo a ser questionado. Já conhecemos, em $O$ nascimento da tragédia, a metafísica do artista ainda presente aqui na Extemporânea, mas sabemos também a conversão nietzschiana que se dará posteriormente, e as duras críticas direcionadas a seu antigo educador e também a Wagner, nas mãos dos quais, diz Nietzsche na Genealogia da moral, a música se transformara num telefone do além ${ }^{27}$.

A crítica nietzschiana ao historicismo, também feita por Schopenhauer em relação a Hegel, conduz-nos novamente àquele questionamento: em relação ao devir, diz ele, "o heroísmo da veracidade consiste em deixar um dia de ser seu joguete. No devir, tudo é oco, mentiroso e inanimado, e também digno do nosso desprezo; o enigma que o homem deve resolver, ele não pode resolvê-lo senão a partir do ser, no ser assim e não outra coisa, no imperecível’"28.

A cultura do homem schopenhaueriano tem como tarefa, afirma Nietzsche, "incentivar o nascimento do filósofo, do artista e do santo [nosso grifo] em nós e fora de nós, e trabalhar assim para a

\footnotetext{
${ }^{22}$ Idem, Ibidem, p. 248-249.

${ }^{23}$ Idem, Ibidem, p. 204.

${ }^{24}$ Idem, Ibidem, p. 199.

${ }^{25}$ Idem, Ibidem, p. 200.

${ }^{26}$ Idem, Ibidem.

${ }^{27}$ Idem, Genealogia da moral, p. 93.

${ }^{28}$ Idem, Consideração Extemporânea III, p. 203. 
realização (Vollendung) da natureza"29. Engendrar indivíduos poderosos: para isto trabalha toda espécie na natureza. Ela necessita tanto do filósofo quanto do artista, para um fim metafísico, para preencher as lacunas que ela, em sua inépcia e inexperiência, deixou em sua criação. Do mesmo modo, o santo nos ensina a dissolução do eu e o "sentimento de igualdade, compaixão (Mitgefühl) e unidade com tudo o que vive (...) Há, para além do nosso ser, algo que nestes momentos se torna um deste lado, e isto porque aspiramos, no mais profundo da nossa alma, estas pontes entre o aqui e o lá"30.

A natureza é pródiga, dispensa aos montes os homens comuns - ou homens correntes (couranten Menschen) como diz Nietzsche - na tentativa de criar os homens superiores. "A natureza é má economista", afirma ele, "suas despesas são bem maiores do que as receitas que ela consegue" - esta metáfora encontra-se já em Schopenhauer: esta e outras metáforas relativas ao comércio em seus escritos têm origem na sua criação, como filho de comerciante, em que recebera, a contragosto, um estudo que visava transformá-lo num substituto do pai, que foi interrompido com o suicídio deste, fato observado pelo próprio Nietzsche na terceira Extemporânea.

Enfim, de forma escassa aparecem aqui e ali os indivíduos superiores, os homens redentores (erlösenden Menschen). O conceito de redenção (Erlösung) foi fundamental também em Schopenhauer na caracterização do gênio e do santo, a despeito da perigosa aproximação ao cristianismo que o termo proporciona. Do mesmo modo, Nietzsche afirma que com o engendramento do homem superior, os solitários e livres de espírito, a natureza aspira à sua redenção ${ }^{31}$. Contudo, no sexto capítulo da terceira Extemporânea, Nietzsche faz notar que o engendramento do santo foi culturalmente impulsionado pelo cristianismo, mas submetido ao egoísmo do Estado: adoecendo, degenerando-se e contradizendo seu sentido original. A partir daí ocorre uma virada no desenvolvimento desta Extemporânea: até a última linha, Nietzsche não falará mais do engendramento do santo, mas somente do filósofo e do artista, para se referir à cultura schopenhaueriana.

É preciso acrescentar ainda, a esta crítica à cultura e à educação da época, a submissão ao egoísmo dos negociantes, que, associada ao egoísmo do Estado e da ciência pura, transforma os homens nos escravos atormentados pelos três "M": Momento (Moment); Maneiras de pensar (Meinungen); Modos de agir (Moden $)^{32}$.

Ao analisar o ensaio de Schopenhauer Sobre a filosofia universitária, Nietzsche apresenta, inspirado não na letra, mas no espírito daquele, as condições para o surgimento do gênio filosófico: liberdade viril de caráter; conhecimento precoce dos homens; não educação para a erudição; não estreiteza patriótica; não obrigação de ganhar o pão com a filosofia; e não subordinação ao Estado.

\footnotetext{
${ }^{29}$ Idem, Ibidem, p. 211.

${ }^{30}$ Idem, Ibidem, p. 211-212.

${ }^{31}$ Idem, Ibidem, p. 234.

${ }^{32}$ Idem, Ibidem, p. 221. 
Ao final, resta-nos suspeitar que na relação de Nietzsche com a filosofia schopenhaueriana, ocorre aquilo que ele próprio diz na Extemporânea a respeito da relação de Schopenhauer com a filosofia kantiana: "ele se apoderou dela sobretudo como um instrumento retórico extraordinário (...) tal como, com o mesmo objetivo, ele se valeu, na época, da mitologia budista e cristã. Ele somente tomou para si uma única tarefa e um milhão de meios para resolvê-la: um único sentido e inúmeros hieróglifos para expressá-lo" ${ }^{\prime 3}$. A confirmação desta suspeita virá anos depois em Ecce Homo, em que Nietzsche confessa a intenção que impulsionou a composição da terceira Extemporânea: "ter em mãos umas tantas fórmulas, signos e meios linguísticos mais (...) De maneira igual serviu-se Platão de Sócrates, como uma semiótica para Platão"34.

\section{Referências}

HALEVY, Daniel. Nietzsche: uma biografia. Trad. Roberto Cortes de Lacerda e Waltensir Durtra. Rio de Janeiro: Campus, 1989.

NIETZSCHE, Friedrich Wilhelm. Sämtliche Werke. Kritische Studienausgabe in 15 Bänden. Herausgegeben von Giorgio Colli und Mazzino Montinari Berlin/München: Walter de Gruyter \& Co./DTV, 1980.

Mário da Silva. 12. ed. Rio de Janeiro: Civilização Brasileira, 2003.

Assim falou Zaratustra: um livro para todos e para ninguém. Trad. . Ecce homo: como alguém se torna o que é. Trad. Paulo César de Souza. São Paulo: Companhia da Letras, 1995.

. Consideração extemporânea III - Schopenhauer como educador. In: NIETZSCHE, Friedrich Wilhelm. Escritos sobre educação. Trad. Noéli Correia de Melo Sobrinho. Rio de Janeiro: PUC-Rio; São Paulo: Loyola, 2009.

São Paulo: Companhia da Letras, 1998.

. Genealogia da moral: uma polêmica. Trad. Paulo César de Souza.

. O Nascimento da Tragédia, ou Helenismo e Pessimismo. Trad., notas e posfácio J. Guinsburg. São Paulo, Companhia das Letras, 1992.

SCHOPENHAUER, Arthur. Sämtliche Werke. Textkritisch bearbeitet und herausgegeben von Wolfgang Frhr. Löhneysen. Darmstadt: Wissenschaftliche Buchgesellschaft, 1968.

- Sobre a filosofia universitária. Trad. Maria Lúcia Mello e Oliveira Cacciola e Márcio Suzuki. São Paulo: Pólis, 1991.

\footnotetext{
${ }^{33}$ Idem, Ibidem, p. 241.

${ }^{34}$ Idem, Ecce Homo, p. 70. 
JARLEE SALVIANO

Received: 05/19/12

Aprovado: 21/12/12

Approved: 12/21/12 